\title{
Identification and classification of open book accounting dimensions
}

\author{
Leila Sadeghi $^{\mathbf{a}^{*}}$ and Iman Jokar ${ }^{\mathrm{b}}$
}

${ }^{a}$ M.A in Accounting, Department of Accounting, Science \& Research Branch, Islamic Azad University, Fars, Iran

${ }^{b}$ Assistant professor of Financial Management, Department of Accounting, Science \& Research Branch, Islamic Azad University, Fars, Iran

\section{H R O N I C L E}

Article history:

Received February 28, 2014

Received in revised format

19 March 2014

Accepted 20 March 2014

Available online

March 232014

Keywords:

Open-book accounting (OBA)

Inter-organizational cost

management (IOCM)

Analytical hierarchy process

(AHP)

\section{A B S T R A C T}

This study aims to identify and to classify Open book accounting (OBA) dimensions according to inter-organizational cost management (IOCM). The study selects six university professors in the field of accounting and by studying the theoretical literature and conducted investigations inside and outside of the country, the OBA dimensions were identified and then they were classified by analytical hierarchy process technique. According to the studies and experts' ideas, four dimensions including nature of data and accounting data disclosure practices, uses of disclosed accounting data, conditions of OBA, cost implementation of OBA were identified as OBA dimensions. The results of our survey indicate that the form of data disclosure as well as coordination and planning among team members played essential role for OBA development. In addition, trust and the cost of the second party were other important factors, which must be considered when OBA is applied in any industry.

\section{Introduction}

Open-book accounting (OBA) is an accounting method where a particular firm reveals the details of the cost of data to special partners. For instance, an automaker may disclose details of products' expenses including parts, direct and indirect payment, manufacturing expenses, corporate overhead, cost of packaging, transportation, services after sale, research and development and profit for its suppliers of raw materials. In other example, the supplier of raw materials discloses its overhead expenses including waste during production, production requirements, depreciation, and insurance and its practical capacity for the buyer. To date, OBA is still a relatively new issue and many business owners prefer not to disclose their financial data. The main reason is that cost data is considered as one of the most confidential and sensitive pieces of data in most firms. Disclosing the data to supply chain partners is a practice that appeared with the spread of lean production and supply in the 1990s (Windolph \& Möller, 2012; Shomakhi, 2011; Munday, 1992). As a result, there are only a few studies

*Corresponding author.

E-mail addresses: leila_sadeghi4712@yahoo.com(L. Sadeghi) 
to investigate the current procedures on the provider-buyer relationships. Some studies indicate that $30 \%$ of suppliers of electronic components offered their products' expenses for the customers and just $10 \%$ of them revealed this kind of data to subcontractors. Inter-organizational cost management is normally associated with various activities, processes or techniques, which help managers, prepare the costs, which are within the inter-organizational borders. All of the inter-organizational cost management methods are in common they are inter-organizational cooperation activities with the common objective of producing value for both partners through restructuring inter-organizational expenses. According to inter-organizational cost management practices, inter-organizational cooperation facilities may influence the expenses in two ways: First, it assists to determine the ways, which increases the relationships between firms and second, it helps business owners as well as buyers and suppliers to detect more methods for reducing the cost of product. Management accounting practices in inter-organizational cost help detect the cost price and reporting and disclosure section.

\section{Related literature}

Kulmala (2002) is believed to be one of the first who performed a discussion on benefits of disclosing a firm's cost component information to other business owners. Kulmala (2002) presented a framework for investigating open-book accounting. Kajüter and Kulmala (2005) gave some insight about the contingency framework and theoretical and managerial applications, contributing to reduce the deficiency in two steps: First, they explained a single case study of a German car manufacturing and, then, they explained the results of a cross-case analysis in three Finnish manufacturing networks and presented six reasons on why open-book accounting failed. Suomala (2010) described that OBA was an accounting template with a seemingly flexible characteristics. He described how OBA could be applied for mitigating the component's price increasing pressures and, thus, controlling the expenses of the products. Suomala described that the best corresponding control archetype for a given OBA application could depend on the inter-organizational cost management activities by participating stakeholders. Rahnamaye Roudposhti and Gholami Jamkarani (2011) performed similar study on OBA application and reported similar results.

Agndal and Nilsson (2010) described that within market procurement specified by a transactional purchasing strategy, different cost data may serve to reduce purchase price. Therefore, data disclosure is limited in scope and scale, occurs primarily during supplier evaluation and selection and depends entirely on an adversarial atmosphere. Hoffjan et al. (2011) described that OBA could be applied in price management and for inter organizational cost management by increasing negotiation pressure on a supplier. $\mathrm{Xu}$ (2011) investigated inter-organizational cost management circumstance, techniques, and built an application framework of cost management in supply chain. Meynardie (2012) investigated the application of OBA in the construction industry by focusing on different components including book contract clauses; appropriate project delivery systems for open book accounting; the kinds of projects, which lend themselves to OBA, and certain advantages and shortcoming associated with the implementation of open book accounting in the study "Innovative Legal Strategies Developed from Challenging Projects”.

\section{Dimensions of Open Book Accounting}

Cost management applications have transcended traditional firm boundaries (Mouritsen et al., 2001; Dekker, 2003; Cooper \& Slagmulder, 2004) and OBA is an emerging phenomenon. The primary reason is that cost data is normally one of the most confidential and sensitive pieces of information in various business units. Disclosing this type of information to supply chain partners is a practice, which is apparent with the emergence of lean production and supply in the 1990s. OBA previously includes three interrelated dimensions including nature of data and the purposes of data disclosure; 
atmosphere of the buyer-supplier relationship, incentives for the supplier to disclose cost data demonstrated in Table 1 as follows,

\section{Table 1}

Difference perspectives of OBA

\begin{tabular}{|c|c|}
\hline Dimensions & Contents \\
\hline Nature of data and accounting data disclosure practices & $\begin{array}{l}\text { (1)Types of disclosed data. } \\
\text { (2)Extent of cost data disclosure } \\
\text { (3) Form of cost data disclosure }\end{array}$ \\
\hline Uses of disclosed accounting data & $\begin{array}{l}\text { (1)Support of strategy formulation } \\
\text { (2)Decision making } \\
\text { (3)Cost planning and control } \\
\text { (4)Performance measurement and evaluation } \\
\text { (5)Product development and supply chain }\end{array}$ \\
\hline Coordination Conditions of open book accounting & $\begin{array}{l}\text { (1) Relationship characteristic } \\
\text { (2) Exchange process } \\
\text { (3) Product characteristic }\end{array}$ \\
\hline Open book accounting implementation cost & $\begin{array}{l}\text { 1) The cost of the sit cost } \\
\text { 2) Sit cost } \\
\text { 3) disallowed cost }\end{array}$ \\
\hline
\end{tabular}

In this paper, according to the previous studies, we have added a new item of OBA, which includes some new cases. The primary objective of data disclosure influences the type of requested data. The conditions of data disclosure will tell us what kinds of data the supplier is willing to share and, consequently, which activities data disclosure could support.

\section{Conceptual model}

As stated in Table 1, OBA includes 4 dimensions including Nature of data and accounting data disclosure practices, Uses of disclosed accounting data, Coordination Conditions of OBA and Open book accounting implementation cost and now sub-dimensions are determined as Fig. 1.

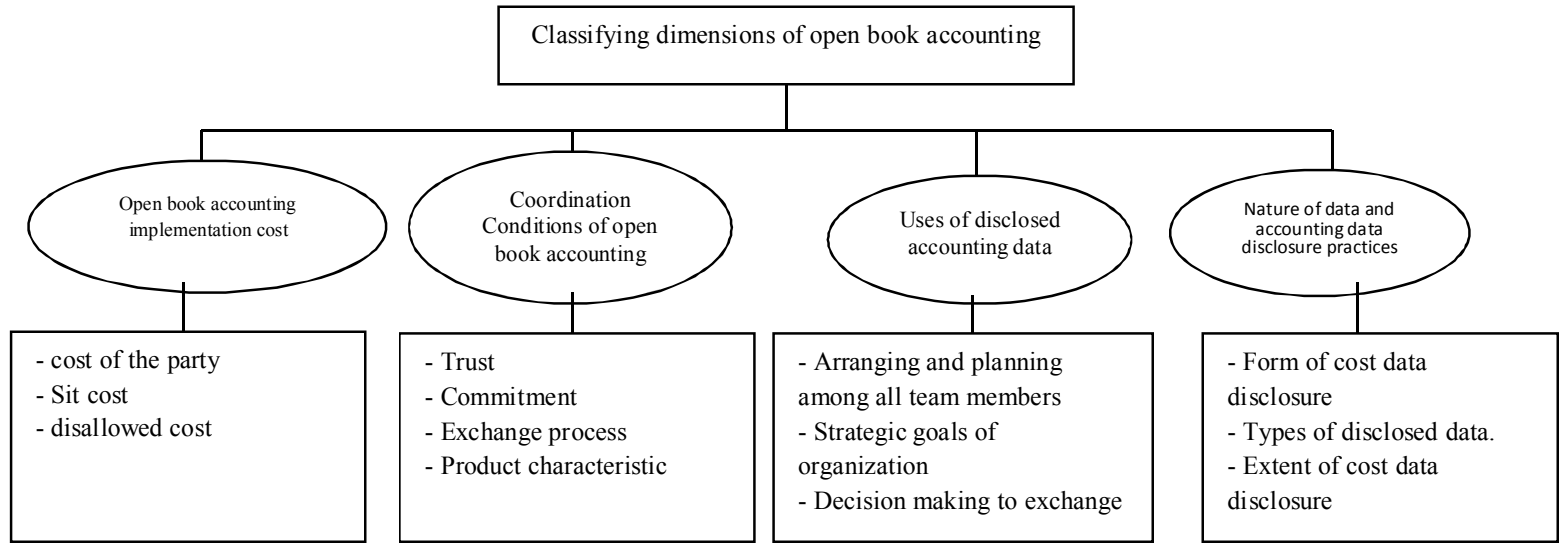

Fig. 1. The conceptual model

As we can see from Fig. 1, first dimension of OBA includes the nature of data and accounting data disclosure practices, which forms the cost data disclosure, different kinds of disclosed data and extent of cost data disclosure. Form of cost data disclosure specifies that we concentrate on providing the data associated with activity history, accounting procedures, accounting changes and post-events after balance sheet. Type of disclosed data includes the data, which must be disclosed by three features: appropriate: giving the minimum amount of data required for users in a way not to confuse them. Equanimity is related to the goal based professional behaviors. Complete is associated with all related important and effective provided data.

FASB: the data are important, effective we assume that the data with these features provide society general interests. Second dimension of OBA includes implementation of disclosed accounting data containing sub-dimensions as arranging and planning among all team members, strategic objectives 
and organization, decision making to exchange. Arranging and planning among all team members' states that conducting an OBA system requires arranging and planning among all team members and the necessary regulation to determine the place where the data is available to all interested groups.

Strategic objectives of firm include decreasing expenses, increasing interests, and enhancing sales. Decision making to exchange states that decision making is a process to reduce distrust, removing doubts about the options in what to be able in choosing reasonably, for instance: someone wants to provide the data for the party and determine he/she receive them or not? Third dimension is of OBA includes sub-dimensions like trust, commitment, exchange process and product characteristics, specifying the parties trust to disclose data. Trust is an element in a firm and industry explaining the kind of communications. Commitment states that commitment is a base for trust; if two parties (seller and buyer) commit to disclose data, it will be probable to disclose sensitive data without communication. Exchange process indicates all sorts of activities and conductions during a transaction. Product characteristics specify the factors considered as important ones for the customer like: usage, durability, quality, price, lifetime. The last dimension of OBA includes OBA implementation costs, which includes the sub-dimensions such as cost of the party, sit cost and disallowed cost. Expenses of the party dimension specify that whether or not the data was disclosed and the consequences; for instance: decreasing profit margin. Sit cost specifies that the seller and buyer may receive all their necessary services in the least cost and distance, from the network. Information network is available as a modern technique for all providers. Firms and providers apply information technology system for investigating information.

\section{Research method}

This research is a kind of applied similar to the work earlier published by Sadeghi and Jokar (2014) and uses a questionnaire for data gathering. First, the necessary information is gathered from the library resources in terms of documents and then some Iranian academic experts' comments are used for the analyze data. To test OBA criteria and sub-criteria, analytical hierarchy process (AHP) is applied (Saaty, 2003). OBA implementation is considered as dependent variable and different challenges for implementation are considered as independent variables. The study was held in 2013. In this research, the statistical society includes six university experts. Data collection in this research is based on AHP questionnaire, which collects the relative importance of dimensions of OBA. According to its goals, this research has 3 phases:

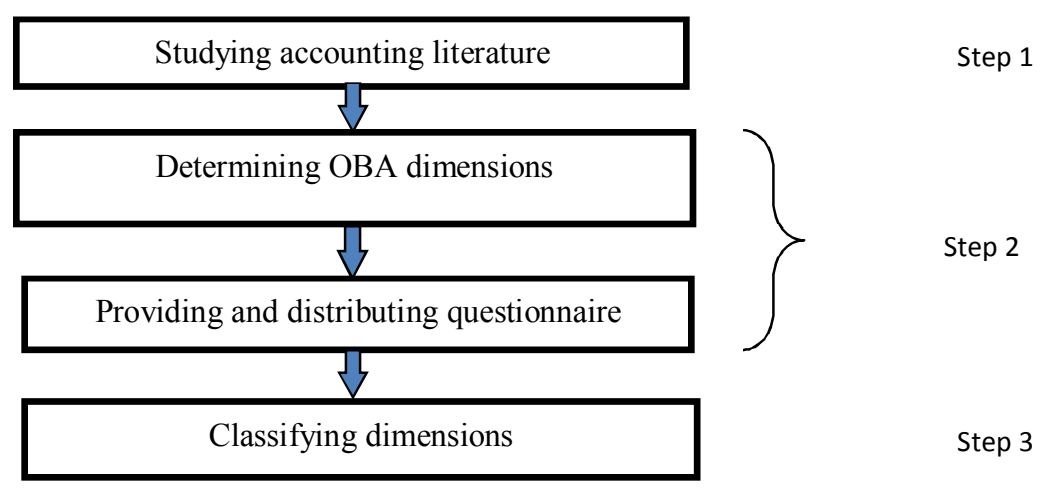

Fig. 2. Conduction process of the research

\section{Data analysis and results}

In the first step, after determining OBA sub criteria, relative importance of each sub criterion is evaluated using traditional pair-wise method. In the second step, the comparison matrix of criteria by a group is calculated based on geometric mean. 
$a_{i j}=\frac{1}{n} \prod_{k=1}^{n} a_{i j}^{k}$.

To measure the priority of OBA sub criteria, normalization and weighted average has been used. There are numerous methods for normalization and we apply the following normalization technique,

$$
R_{i j}=a_{i j} / \sum a_{i j} .
$$

The third step: after normalization of each line values, weighted average is computed. The obtained values of weighted average indicate each criterion weight. The results are shown in hierarchical tree in Fig. 3. According to Fig. 3, there are four main levels including "Nature of data and accounting data disclosure practices", "Uses of disclosed accounting data", "Coordination conditions of open book accounting" and "Open book accounting implementation cost". Each of these criteria is broken down into other components. The consistency ratios of all components are well below the acceptable limit, which validates the overall survey.

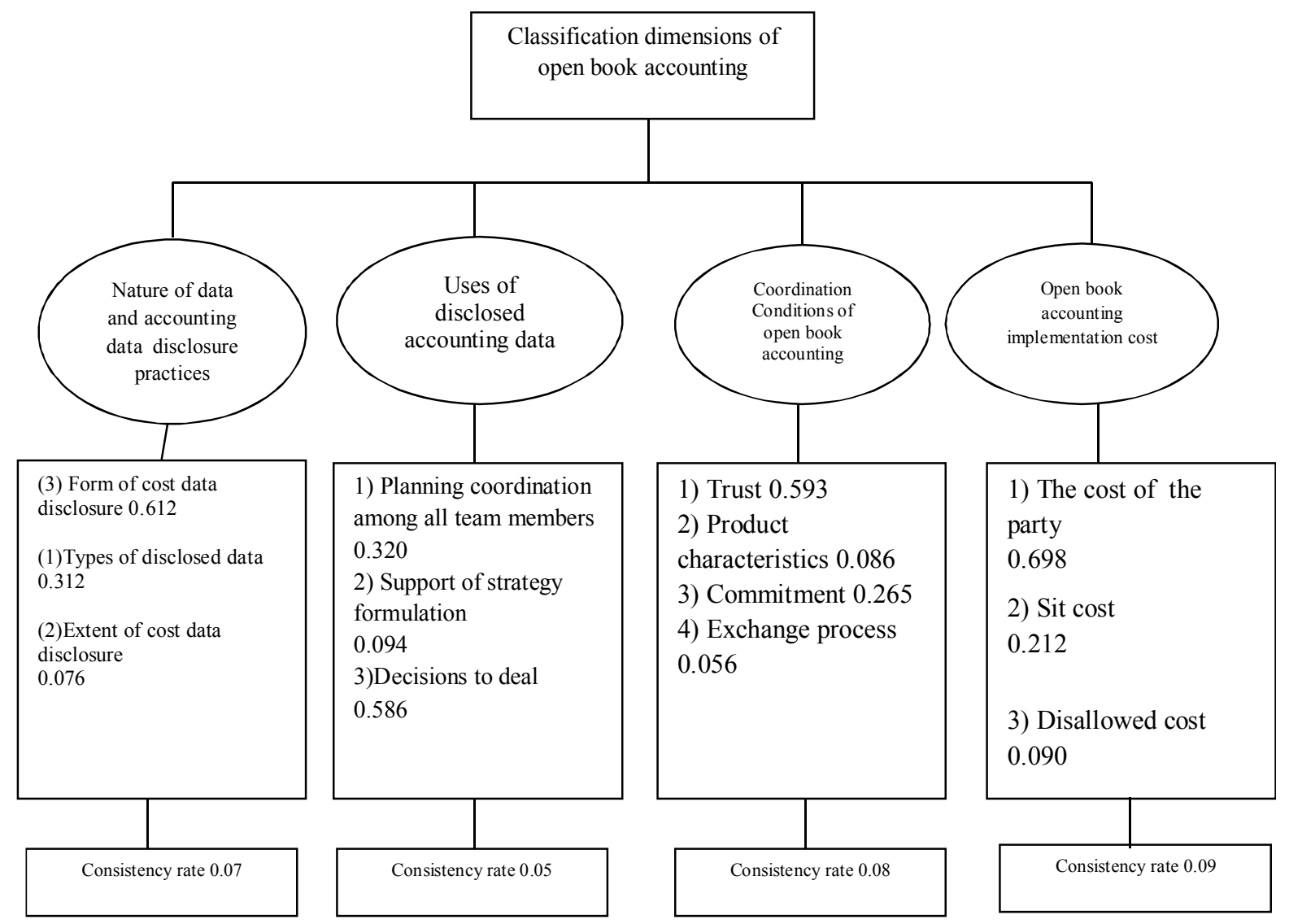

Fig. 3. Data analysis and results

\section{Discussion and conclusion}

According to experts' opinions about the nature of data and accounting data disclosure practices methods (types of disclosed data, extent of cost data disclosure, form of cost data disclosure), due to cost management, the form of data disclosure is the most important dimension; it means that the form of data disclosure should be focused more. The results are also consistent with findings reported by Sadeghi and Jokar (2014). In terms of the second item, "Uses of disclosed accounting data", decision making is the first priority followed by planning coordination among all team members and support of strategy formulation is the last priority. Again, these results are also consistent with other findings 
reported earlier by Sadeghi and Jokar (1014). The results of our survey in other two components indicate that trust and the cost of the second part play essential role on development of OBA.

\section{References}

Agndal, H., \& Nilsson, U. (2010). Different open book accounting practices for different purchasing strategies. Management Accounting Research, 21(3), 147-166.

Cooper, R., \& Slagmulder, R. (2004). Interorganizational cost management and relational context. Accounting, Organizations and Society, 29(1), 1-26.

Dekker, H. C. (2003). Value chain analysis in interfirm relationships: a field study. Management Accounting Research, 14(1), 1-23.

Kajüter, P., \& Kulmala, H. I. (2005). Open-book accounting in networks: Potential achievements and reasons for failures. Management Accounting Research, 16(2), 179-204.

Kulmala, H.I. (2002).Open-book accounting in networks. The Finnish Journal of Business Economics, 52(2), 157-177.

Hoffjan, A., Lührs, S., \& Kolburg, A. (2011). Cost Transparency in supply chains: demystification of the cooperation tenet. Schmalenbach Business Review, 63, 230-251.

Hoffjan, A., \& Kruse, H. (2006). Open book accounting als Instrument im Rahmen von Supply Chains-Begriff und praktische Relevanz. Controlling \& Management, 50(2), 94-99.

Hoffjan, A., \& Kruse, H. (2006). Open book accounting in supply chain: How is it used in practice?. Cost Management, 20(6), 40-47.

Meynardie, B., \& Nagorzanski, A. (2012). The use of open book accounting in cost reimbursable contracts. $18,38-3$

Möller, K., Windolph, M., \& Isbruch, F. (2011). The effect of relational factors on open-book accounting and inter-organizational cost management in buyer-supplier partnerships. Journal of Purchasing and Supply Management, 17(2), 121-131.

Mouritsen, J., Hansen, A., \& Hansen, C. Ø. (2001). Inter-organizational controls and organizational competencies: episodes around target cost management/functional analysis and open book accounting. Management Accounting Research, 12(2), 221-244.

Munday, M. (1992). Accounting cost data disclosure and buyer-supplier partnerships - a research note. Management Accounting Research, 3(3), 245-250.

Rahnamaye Roudposhti, F., \& Gholami Jamkarani, R. (2011). Inter-organizational cost management (IOCM): concepts, procedures and Requirements. Management accounting Magazine, 4, 9.

Romano, P., \& Formentini, M. (2012). Designing and implementing open book accounting in buyersupplier dyads: A framework for supplier selection and motivation. International Journal of Production Economics, 137(1), 68-83.

Saaty, T. L. (2003). Decision-making with the AHP: Why is the principal eigenvector necessary. European journal of operational research, 145(1), 85-91.

Sadeghi, L., \& Jokar, I. (2014). Identification and classification of open book accounting dimensions by considering inter-organizational cost management: A case study of petrochemical companies listed in Tehran Stock Exchange. Management Science Letters, 4, 295-302.

Shomakhi, H.R., (2011). Cost Reengineering in commercial insurance companies. Management Accounting Magazine, 4, 9.

Suomala, P., Lahikainen, T., Lyly-Yrjänäinen, J., \& Paranko, J. (2010). Open book accounting in practice-exploring the faces of openness. Qualitative Research in Accounting \& Management, 7(1), 71-96.

Windolph, M., \& Möller, K. (2012). Open-book accounting: Reason for failure of inter-firm cooperation?. Management Accounting Research, 23(1), 47-60.

$\mathrm{Xu}, \mathrm{C}$. (2011, August). Interorganizational Cost Management in Supply Chain Based on Open Book Accounting. In Management and Service Science (MASS), 2011 International Conference on (pp. 1-4). IEEE. 